\title{
Reducing the Number of Hospitalization Days for COPD: Setting up a Transmural-Care Pathway
}

This article was published in the following Dove Press journal:

International Journal of Chronic Obstructive Pulmonary Disease

\author{
Lotte F Westbroek (D) \\ Margot Klijnsma $\mathbb{D}^{\prime}$ \\ Philippe Salomé2 \\ Lidewij M Sekhuis (D) ${ }^{1,3}$ \\ Emiel Rolink ${ }^{3}$ \\ Erny Korsmit ${ }^{4}$ \\ Huib AM Kerstjens (D) 1,3 \\ On behalf of the LAN \\ COPD Care Pathway Study \\ Group

\begin{abstract}
'Department of Pulmonary Diseases, University of Groningen, and University Medical Center Groningen, Groningen Research Institute for Asthma and COPD GRIAC, Groningen, The Netherlands; ${ }^{2}$ General practitioner, private practice, IJsselstein, The Netherlands; ${ }^{3}$ Lung Alliance Netherlands (LAN), Amersfoort, The Netherlands; ${ }^{4}$ Bravis Hospital, The Netherlands and Senior Advisor Healthcare Networking at Korsmit Zorgadvies, Bergen Op Zoom, The Netherlands
\end{abstract}

Background: Many patients with chronic obstructive pulmonary disease (COPD) experience exacerbations of symptoms, leading to a large burden on patients and the health system and costs to society. To address this burden, a $25 \%$ reduction in number of hospitalization days for COPD exacerbations was recently declared a national goal in the Netherlands, to be achieved in 5 years.

Methods: A national care pathway was designed following an established managed clinical pathway setup, which involved prior national surveys and the identification of ten key elements. The concept was discussed, made locally applicable, and finally tested in eight regions containing eleven hospitals and surrounding primary-care groups in a prospective cohort study. All patients were followed for 1 year, starting at hospitalization.

Results: In total, 752 patients gave informed consent and participated (mean age 70 years, $58 \%$ female). Of these, 120 (16\%) died within a year. The median length of index hospitalization was 5 days, and $43 \%$ had at least one rehospitalization within 1 year (range $0-8$ ). There was a $19.4 \%$ reduction in number of total hospitalization days, without a decrease in health-related quality of life or perceived quality of care. Elements that contributed significantly to the reduction were contact in the first week after hospitalization, and during the year of follow-up pharmacological and nonpharmacological smoking-cessation guidance, checks on inhalation technique, and discussion of lung-attack plan.

Discussion: With concerted action between patients and health workers in the hospital and in the community, a large reduction in number of hospitalization days can be achieved. The program was quite demanding for both patients and health workers. In our subsequent national implementation plan after this pilot study, we have named the major contributors to success and advocate the stepwise introduction of the elements in light of feasibility.

Keywords: COPD, National Action Program, managed-care pathway, hospitalization

\section{Introduction}

Many patients with chronic obstructive pulmonary disease (COPD) experience exacerbations of symptoms. ${ }^{1}$ Frequent exacerbations are associated with lower

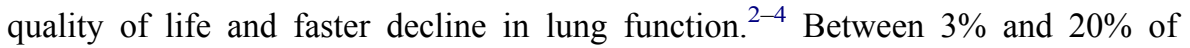
patients require at least one hospital admission per year, and mortality rates after admission are very high, up to $43 \%$ after 2 years. ${ }^{2,5-8}$ The economic burden of COPD is thus substantial. In the Netherlands, it is estimated that hospitalizations account for $33 \%-57 \%$ of total costs of COPD, depending on the survey method. ${ }^{9,10}$ In many countries, this percentage is even higher, up to $84 \%{ }^{5}$ This economic burden is becoming increasingly difficult to bear. As an additional worry, the number of patients with COPD will increase in coming years, mainly because of
Correspondence: Huib AM Kerstjens Department of Pulmonary Diseases, University Medical Center Groningen, Room S3.I3I (AAII), Postbox 30.00I, Groningen $9700 \mathrm{RB}$, The Netherlands

Tel +3I $50361-0280$

Fax +31503619320

Email h.a.m.kerstjens@umcg.nl
International Journal of Chronic Obstructive Pulmonary Disease 2020:15 2367-2377

2367

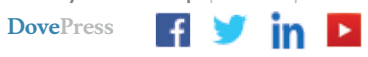

http://doiorg/ $10.2147160 \mathrm{cos} 242914$ 
aging of the population and past smoking, thereby adding to the challenges of appropriate care.

With the aim of improving the level of care in the Netherlands while curbing the costs and burden to patients and society, the Lung Alliance Netherlands (LAN) started a National Action Program for Chronic Lung Diseases with five SMART (specific, measurable, achievable, realistic, and timely) goals. The first of these goals was to reduce the number of days hospitalized because of obstructive-airway diseases by $25 \%$ in 5 years. ${ }^{11,12}$ To reach this goal, a managed-care pathway for COPD was designed. We defined the goal as the reduction in hospitalization days plus at least maintaining health-related quality of care and patient perception of quality of care. In this paper, we describe the design of the care pathway, the results of the pilot study assessing which interventions were successful, and discuss recommendations for nationwide implementation of the care pathway.

\section{Methods}

\section{Care-Pathway Design}

To design, implement and evaluate the care pathway, the seven-phase method of the European Pathway Association was used..$^{13}$ The seven phases are screening, project management, assessment of current situation, care-pathway development, implementation, evaluation, and continuous follow up. Given the reach of the overriding national goal $-25 \%$ reduction in hospitalization days in 5 years - it was clear that a transmural endeavor was needed, ie, with equal participation from in-hospital and community-based experts. Care was taken to ensure patient participation via the Dutch Lung Foundation, next to pulmonary physicians, general practitioners, nurses, psychologists, dieticians, physiotherapists, pharmacists, and managed care-pathway specialists. The aforementioned participants for defining the content of the care pathway were recruited by formal invitation as delegates from their respective professional societies or via the Lung Foundation for patients.

\section{Assessment of Current Situation}

The current situation, phase 3, was assessed nationwide and locally with patients and health-care providers. Nationally, in close collaboration with the Dutch Lung Foundation, two patient focus groups were recruited from members of their patient panel and interviewed. Also nationally, all pulmonary physicians and GPs were surveyed on the organization of care in their hospital or GP's office, and on bottlenecks for better care. Via the public website of the Dutch Lung Alliance, some specifically involved other health-care providers such as respiratory nurses and physiotherapists, also responded to the survey.

All hospital regions (ie, hospitals with surrounding GP practices) in the Netherlands were invited to participate in making and piloting the COPD-care pathway. Of 92 regions, 33 responded, of which eight regions, comprising eleven hospitals, were selected, based on equal spread in geographic region and setting (academic, large teaching, local hospital). At the start of the study in the participating regions, patient healthrelated quality of life and perceived quality of care were assessed in a standardized manner by the Clinical COPD Questionnaire (CCQ), ${ }^{14}$ Consumer Quality Index (CQI) - hospitalizations, CQI — asthma and COPD. ${ }^{15,16}$ These questionnaires were repeated toward the end of the study. The same questions were asked to patients in six control regions that had expressed interest in participating, but were not selected (again based on geographic spread). Hospitalization rates and lengths of COPD hospitalizations in the study regions were assessed where possible in 2013 and again in 2018 .

\section{Defining the Pathway}

In phase 4 , the start of the pathway was defined by hospitalization, and patients were to be followed for 1 year each primarily to document number of hospitalization days and other health-care utilization and to determine factors associated with fewer hospitalization days over a year. The pathway described here was first conceived in an iterative process in dedicated meetings by national delegates from the aforementioned caregiver groups and patients to reach consensus on elements deemed most pivotal for a successful transmural pathway. To guide these decisions, the baseline data from phase 3 were used, and literature searches (unsystematic) were performed for successful interventions documenting reductions in hospitalization days. The literature base found at the time was small and consisted mainly of pharmacological treatments in the hospital. Few evidence-based nonpharmacological interventions in and outside of the hospital were found. In our consensus meetings, however, we estimated that the largest additionally achievable gains were to be nonpharmacological. The following ten elements were selected to be part of the care pathway. 
- Integral health status, to be screened on day 2 of the hospitalization, and with full assessment of coping and adaptation to be planned outside the hospital, including follow-up on items identified. Screening for anxiety and depression was also performed. We prioritized already on day 2 the evaluation of factors contributing to the hospitalization, expectations of the hospitalization by caregivers and the patient, and identifiable factors likely to contribute to successful discharge.

- Individual care plan/lung attack (exacerbation) action plan, to be discussed with patients and their loved ones, starting during hospitalization and iteratively at home, including updates.

- Advance care planning/palliative care. The fact that hospitalization for a COPD exacerbation is associated with mortality of up to $43 \%$ in 2 years was deemed a sufficient reason for starting these discussions without need of further identification of patients at even further increased risk of shortened survival. ${ }^{6-8}$

- Medication and therapy compliance, with special focus on inhalation technique, repeated assessments while on the hospital ward, and again after discharge. Additionally, encourage as much as possible the use of the same inhalation medication and device as at home to practice and gain confidence in home medication.

- Smoking cessation through motivational techniques and pharmacological treatment, again starting on the ward and continued during the year at home.

- Mobility and exercise, early guidance by a physiotherapist for all patients on the ward, and where necessary at home. Formal rehabilitation was offered for after discharge.

- Nutritional status assessment at hospitalization, and action taken as needed in or with outreach to outside the hospital.

- Comorbidity, broad alertness, and treatment as necessary.

- Other care according to guidelines (mostly pharmacological). A national multidisciplinary guideline, specifically aimed at the treatment of COPD exacerbations in the hospital, was made in parallel to the development of this care pathway.

- Monitoring and logistics: assessments of quality of life, dedicated planning of consultations with patients and loved ones. The first of these consultations after discharge was planned within a week to prevent early relapse and was coordinated by a case manager.
In our care pathway, we were careful to describe what needed to be done or provided, not who should do it. It was for the different regions to decide what was feasible for whom.

\section{Patients and Centers}

The care pathway described was subsequently tested in eight pilot regions (start of phase 5), consisting of eleven participating hospitals (12\% of all Dutch hospitals) and associated regional primary-care groups. The regions were guided in translating the ten elements into practical, local protocols, including documenting who was responsible for what part of the managed-care pathway. Toolboxes were created centrally to facilitate implementation. In each region, the first 100 patients admitted for an exacerbation of COPD for the first time since the start of the study were recruited. This was labeled the index hospitalization. All additional hospitalizations for COPD within 1-year followup per individual were also treated as per the pathway. Since care was deemed to be optimal care and no interventions were experimental, the study had the need for formal approval waived by the Medical Ethics Committee of Groningen. However, central data collection using a webbased online database, OpenClinica, was done only with written informed consent.

\section{Statistical Analyses}

Starting at the initial hospitalization, a trajectory of 1 year per patient was started, during which data were collected during admission, and when applicable readmissions, as well as during other planned and unplanned visits to all other health-care providers, especially GPs. In this lowbudget cohort study, we encountered missing data because of mortality and other reasons. Where pivotal questions documenting whether specific interventions had been performed were not completed, the items were conservatively classified as "not performed".

In the statistical part of our implementation study, we were above all interested in which interventions from our extensive program were associated with fewer hospitalization days. To account for variable follow-up, hospitalization days were censored at 1 year and recalculated as percentage of the period hospitalized in further statistical analyses. The natural logarithm of this percentage was used in analyses to normalize the distribution and allow for linear regression. We anticipated a few baseline characteristics, especially age, GOLD stage, and smoking status, to be related to hospitalizations and checked these 
factors first (Table 3). Subsequently, multiple linear regression, corrected for significant baseline characteristics and follow-up length, was used to analyze correlations between interventions and the percentage of period hospitalized. The threshold for statistical significance was $P \leq 0.05$. All statistical tests were performed using IBM SPSS software.

\section{Results}

From January 2015 to August 2018, 752 patients were managed in the care pathway and provided written informed consent to be included in the analyses. The baseline characteristics of the study group are depicted in

Table I Baseline Characteristics $(n=752)$

\begin{tabular}{|c|c|c|}
\hline \multicolumn{2}{|l|}{$\begin{array}{l}\text { Age, years (mean } \pm S D \text { ) } \\
\text { Female }(\%) \\
\text { BMI, median (range) } \\
\text { Current smoker }(\%)\end{array}$} & $\begin{array}{l}69.6 \pm 10.0 \\
58.2 \\
24.0(11.4-52.6) \\
38.2\end{array}$ \\
\hline \multicolumn{2}{|c|}{$\begin{array}{l}\text { Number of comorbidities, median (range) } \\
\text { Congestive heart failure (\%) }\end{array}$} & $\begin{array}{l}1.0(0-7) \\
7.3\end{array}$ \\
\hline Respiratory medication (\%) & $\begin{array}{l}\text { Only LABA } \\
\text { Only LAMA } \\
\text { LABA + ICS } \\
\text { LAMA + ICS } \\
\text { LABA + LAMA } \\
\text { LABA + LAMA } \\
+ \text { ICS } \\
\text { Other }\end{array}$ & $\begin{array}{l}2.8 \\
5.7 \\
21.8 \\
2.1 \\
11 \\
44.0 \\
\\
12.6\end{array}$ \\
\hline \multicolumn{2}{|c|}{$\begin{array}{l}\text { Prednisolone maintenance treatment (\%) } \\
\text { Antibiotic maintenance treatment (\%) } \\
\text { Prednisolone in last } 4 \text { weeks (\%) } \\
\text { Oxygen supplementation at home (\%) } \\
\text { FEV } \% \text { predicted (mean } \pm \text { SD) }\end{array}$} & $\begin{array}{l}13.0 \\
10.6 \\
46.0 \\
16.8 \\
47.0 \pm 18.7\end{array}$ \\
\hline GOLD (\%) & $\begin{array}{l}\text { I } \\
\text { II } \\
\text { III } \\
\text { IV }\end{array}$ & $\begin{array}{l}5.5 \\
33.0 \\
43.5 \\
18.0\end{array}$ \\
\hline $\begin{array}{l}\text { Hospital admissions due to } \\
\text { COPD exacerbation in prior } \\
\text { year (\%) }\end{array}$ & $\begin{array}{l}0 \\
1 \\
2 \\
>3\end{array}$ & $\begin{array}{l}66.5 \\
22.2 \\
6.9 \\
4.4\end{array}$ \\
\hline $\begin{array}{l}\text { COPD exacerbations in prior } \\
\text { year }(\%)\end{array}$ & $\begin{array}{l}0 \\
1 \\
2 \\
>3\end{array}$ & $\begin{array}{l}51.0 \\
25.2 \\
13.9 \\
9.9\end{array}$ \\
\hline
\end{tabular}

Abbreviations: BMI, body-mass index; LABA, long-acting $\beta_{2}$-agonist; LAMA, longacting muscarinic antagonist; ICS, inhaled corticosteroid; FEV volume in I second; GOLD, Global Initiative for Chronic Obstructive Lung Disease.
Table 1. Over the 1-year follow-up per patient, 120 patients died (16\%), and 12 additional patients were lost to follow-up for different reasons (Table 2). The median follow-up was 365 days as expected. The median percentage of time hospitalized was $2.74 \%$ (range 0.3 - 91\%). Number of days hospitalized and number of hospitalizations during the 1-year follow-up are depicted in Figures 1 and 2, respectively. As expected, the percentage of period hospitalized was significantly greater with lower $\mathrm{FEV}_{1}$ percentage predicted, oxygen supplementation at home, prednisolone or antibiotic maintenance treatment, and more prior COPD exacerbations or hospital admissions due to COPD exacerbation (Table 3), and thus these parameters were entered as covariates in the final analyses.

\section{Interventions}

Interventions significantly correlated with less hospitalization were contact in the first week after discharge from the hospital, starting nonpharmacological or pharmacological smoking-cessation guidance later during the year (analyzed only in the smoker group), reviewing the patient's lung-attack action plan later during the year, and checking the medication-inhalation technique later during the year (Table 4). To our surprise, checking the medication-inhalation technique during hospitalization was negatively correlated with the percentage of period hospitalized.

\section{Regional Differences}

There was considerable variability among the regions in implementation of the different interventions. As an example, Figure 3 shows the variability in contact between caregiver and patient in the first week after discharge from the hospital, and the percentage of those contacts that were actually home visits.

\section{Overall COPD Hospitalization Data}

In five of the eight participating regions, it was possible to collect regional data on overall number of hospitalization days in 2013, ie, before the start of this managed-care pathway, and in 2018 (Figure 4). In four of these five regions, overall admission days and percentage of readmissions were reduced during the pilot year in comparison to 2013 , amounting to an overall reduction of $19.4 \%$.

\section{Health-Related Quality of Life and Patient-Perceived Quality of Care}

CCQ data were collected from 590 patients in 2013 and 401 in 2018 , independently of the interventional study. 
Table 2 Main Follow-Up Data

\begin{tabular}{|c|c|c|c|c|}
\hline & & $\mathbf{n}$ & & \\
\hline \multicolumn{2}{|l|}{ Died } & $120(16 \%)$ & & \\
\hline \multirow[t]{2}{*}{ Other reasons for incomplete follow-up } & $\begin{array}{l}\text { Moving away } \\
\text { Stopped participation } \\
\text { Other }\end{array}$ & $\begin{array}{l}1 \\
3 \\
8\end{array}$ & & \\
\hline & & Mean \pm SD & Median & Range \\
\hline \multicolumn{2}{|c|}{ Number of hospital admissions (including index) } & $1.8 \pm 1.2$ & I & $1-8$ \\
\hline \multicolumn{2}{|l|}{ Patients with at least one readmission (\%) } & 43 & & \\
\hline \multicolumn{2}{|l|}{ Follow-up (days) } & $307.2 \pm 107.6$ & 365 & $2-365$ \\
\hline \multicolumn{2}{|l|}{ Percentage of period hospitalized } & $6.2 \pm 11.5$ & 2.7 & $0.3-90.9$ \\
\hline \multicolumn{2}{|l|}{ Length of stay of index hospitalization } & $6.9 \pm 5.5$ & 5 & $0-55$ \\
\hline
\end{tabular}

Table 3 Correlations of Baseline Characteristics with Percentage of Period Hospitalized

\begin{tabular}{|c|c|c|c|c|c|}
\hline & & \multirow[t]{2}{*}{$\beta$} & \multicolumn{2}{|l|}{$95 \% \mathrm{Cl}$} & \multirow[t]{2}{*}{ P-Value } \\
\hline & & & Lower & Upper & \\
\hline \multicolumn{2}{|l|}{ Sex } & -0.095 & -0.219 & 0.030 & 0.14 \\
\hline \multicolumn{2}{|l|}{ Age, years } & 0.003 & -0.003 & 0.009 & 0.33 \\
\hline \multicolumn{2}{|l|}{ FEV 1 \% predicted } & -0.007 & -0.01 & -0.003 & $0.00 *$ \\
\hline \multirow[t]{3}{*}{ Smoking status } & Ex-smoker & 0.021 & -0.274 & 0.316 & 0.89 \\
\hline & Current smoker & -0.092 & -0.394 & 0.209 & 0.55 \\
\hline & Unknown & -0.266 & -0.624 & 0.093 & 0.15 \\
\hline \multicolumn{2}{|c|}{ Inhaled corticosteroids } & -0.038 & -0.170 & 0.095 & 0.58 \\
\hline \multicolumn{2}{|c|}{ Oxygen supplementation at home } & 0.315 & 0.153 & 0.477 & $0.00 *$ \\
\hline \multicolumn{2}{|c|}{ Prednisolone maintenance treatment } & 0.246 & 0.067 & 0.426 & $0.01 *$ \\
\hline \multicolumn{2}{|c|}{ Antibiotic maintenance treatment } & $0.24 I$ & 0.045 & 0.438 & $0.02 *$ \\
\hline \multicolumn{2}{|c|}{ Number of COPD exacerbations in prior year } & 0.084 & 0.039 & 0.129 & $0.00 *$ \\
\hline \multicolumn{2}{|c|}{ Number of hospital admissions due to COPD exacerbation in prior year } & 0.191 & 0.128 & 0.253 & $0.00 *$ \\
\hline
\end{tabular}

Notes: $* P<0.05 . \beta$ is the standardized regression coefficient

CCQ scores deteriorated marginally in the study regions (2.86 in 2013 to 3.02 in 2018), as well as in the control regions (2.87 to 2.89). The changes found were not clinically significant (minimal clinically important difference 0.4 ) or statistically significantly different from each other. Patient-perceived quality of care regarding hospitalization for COPD and COPD care in general were assessed by the respective CQIs: the CQI for COPD hospitalization improved slightly in both the study regions and the control regions (by 0.07 and 0.02 respectively), a small difference of 0.05 in favor of the study regions not being significant. Similarly, the perceived quality of care for COPD in general showed a small difference of 0.06 in favor of the study regions.
Minimal clinically important differences have not been provided for either scale.

\section{Discussion}

Our managed-care pathway combined in the primary and secondary care setting led to fewer hospitalization days over 1 year of follow-up, without compromising quality of life or perceived quality of care. We believe this is an important outcome, since exacerbations in general and undoubtedly those leading to hospitalizations impact patient quality of life and well-being, while also being responsible for approximately half of all costs for COPD. Any successful strategy to curb the number of days in hospital should be greeted with enthusiasm, especially when numbers of 


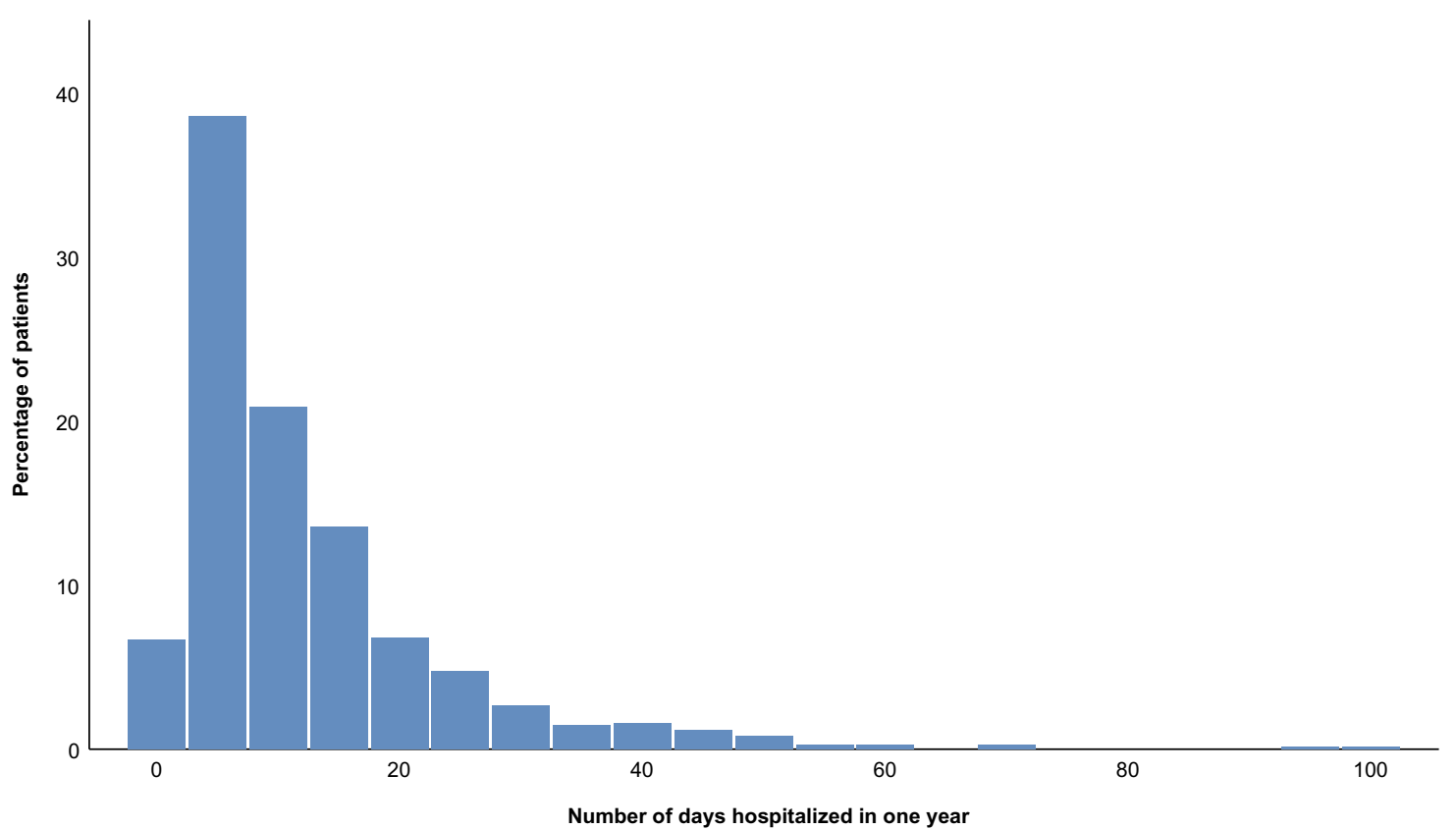

Figure I Number of days hospitalized in I year (including index hospitalization).

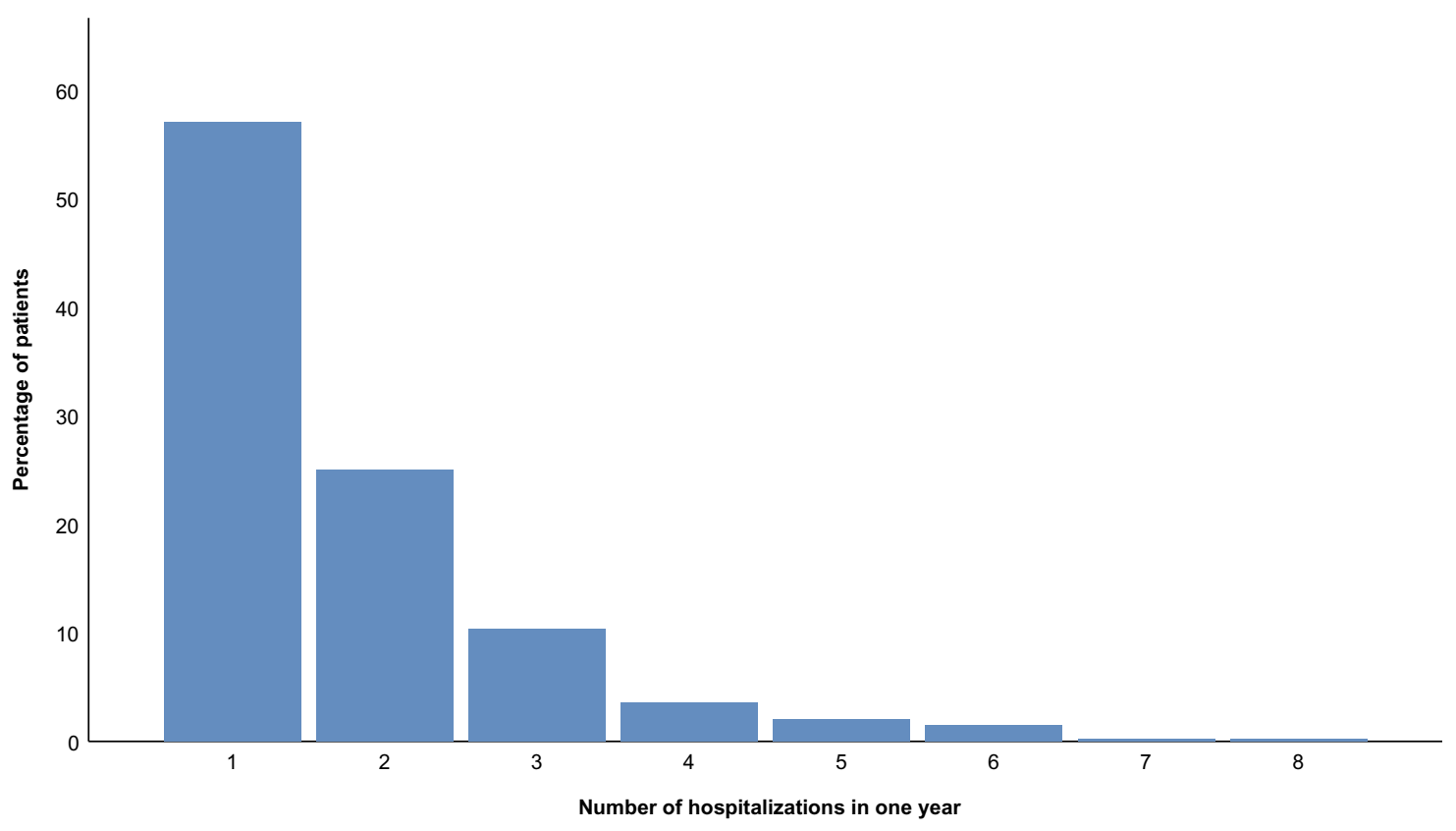

Figure 2 Number of hospitalizations in I year (including index hospitalization).

patients with COPD are still on the rise, due to aging of the population and (past) smoking behavior.

The overall first goal of our National Action Program for Chronic Lung Diseases is a $25 \%$ reduction in number of days hospitalized because of COPD in 5 years. ${ }^{12}$ In our cohort study, we followed all patients for just 1 year. When comparing data from the same regions before and at the end of our study (2013-2018), we found an overall reduction of $19.4 \%$, which is considerable. Five elements contributed significantly to fewer hospitalization days: contact in first week after hospitalization and pharmacological and nonpharmacological smoking-cessation guidance, checking inhalation technique, and discussion of lung-attack plan during the year of follow-up. 
Table 4 Correlation of Interventions with Percentage of Period Hospitalized

\begin{tabular}{|c|c|c|c|c|c|c|c|}
\hline & \multicolumn{2}{|c|}{ Count } & \multicolumn{2}{|c|}{$\begin{array}{l}\text { Percentage } \\
\text { period } \\
\text { hospitalized }\end{array}$} & \multicolumn{2}{|l|}{$95 \% \mathrm{Cl}$} & \multirow[t]{2}{*}{$\begin{array}{l}\text { P-value } \\
\text { (corrected) }^{\#}\end{array}$} \\
\hline & $\mathrm{No}^{\&}$ & Yes & $\mathrm{No}^{\&}$ & Yes & Lower & Upper & \\
\hline Contact in first week after discharge & 336 & 416 & 3.29 & 2.43 & -0.293 & -0.008 & $0.04 *$ \\
\hline Home visit as contact in first week & 189 & 227 & 2.42 & 2.43 & -0.119 & 0.244 & 0.50 \\
\hline Home visit later during the year & 576 & 176 & 2.51 & 3.01 & -0.043 & 0.276 & 0.15 \\
\hline $\begin{array}{l}\text { Starting nonpharmacological smoking-cessation guidance during } \\
\text { hospitalization for smokers }\end{array}$ & 216 & 49 & 2.51 & 2.07 & -0.233 & 0.337 & 0.72 \\
\hline $\begin{array}{l}\text { Starting nonpharmacological smoking-cessation guidance later during year } \\
\text { for smokers }\end{array}$ & 243 & 22 & 2.53 & 1.37 & -0.825 & -0.075 & $0.02 *$ \\
\hline $\begin{array}{l}\text { Starting pharmacological smoking-cessation guidance during hospitalization } \\
\text { for smokers }\end{array}$ & 219 & 46 & 2.19 & 2.74 & -0.182 & 0.367 & 0.51 \\
\hline $\begin{array}{l}\text { Starting pharmacological smoking-cessation guidance later during year for } \\
\text { smokers }\end{array}$ & 253 & 12 & 2.49 & 1.40 & -1.074 & -0.050 & $0.03 *$ \\
\hline Lung-attack action plan reviewed during hospitalization & 316 & 436 & 2.27 & 3.28 & -0.110 & 0.175 & 0.66 \\
\hline Lung-attack action plan reviewed later during year & 473 & 279 & 3.29 & 2.19 & -0.293 & -0.010 & $0.04 *$ \\
\hline Inhalation technique checked during hospitalization & 222 & 530 & 2.19 & 3.01 & 0.042 & 0.351 & $0.0 I^{*}$ \\
\hline Inhalation technique checked later during year & 433 & 319 & 3.56 & 2.19 & -0.328 & -0.043 & $0.01 *$ \\
\hline Expectations of patient/family discussed during hospitalization & 558 & 194 & 2.74 & 2.47 & -0.121 & 0.194 & 0.65 \\
\hline Palliative care, care plans discussed during hospitalization & 576 & 176 & 2.56 & 3.01 & -0.029 & 0.303 & 0.11 \\
\hline Palliative care, care plans discussed later during year & 689 & 63 & 2.74 & 2.73 & -0.225 & 0.226 & 1.00 \\
\hline Day 2 meeting conducted & 293 & 459 & 3.29 & 2.43 & -0.276 & 0.008 & 0.06 \\
\hline
\end{tabular}

Notes: ${ }^{\circledR}$ No or unknown; ${ }^{*}<0.05 ;{ }^{\#}$-values from linear regression model corrected for significant baseline variables (Table 3 ) and length of follow-up.

A significant and important contribution was patient contact in the first week after discharge (though in some cases, actually in the first 2 weeks). Given the generally high readmission rates in the first days after discharge, ${ }^{17}$ this should make sense, but studies so far have been mixed in documenting the contribution of early contact to readmission rates. ${ }^{18,19}$ In this pilot, checks were not only on whether all instructions and medication schemes were well understood and sustainable but also on anxiety and social coping. Due to regional and sometimes logistic differences, some contacts were performed as home visits, whereas others were GP or outpatient visits or telephone contact only. We had anticipated that home visits would ultimately lead to the best results, and this was also corroborated by impressions of the health workers involved, but we were unable to demonstrate this. Our result could also be compatible with a (justified) selection in who was to be visited at home and who not. We were insufficiently informed on this latter selection aspect.

In line with the value of this early contact after discharge was the value of repeated discussion of the lungattack action plan. Self-management plans in general have been proven to improve care in COPD. ${ }^{20-22}$ In the
Netherlands, we attempt not to use the general medical term "exacerbation" and have reframed this to use the phrase "lung attack" to facilitate communication with patients and their beloved. ${ }^{23}$ It also serves to stress to both patients and caregivers that 2-year mortality after a lung attack (COPD) is higher than after a heart attack. The central part of this lung-attack plan is what to do in cases of a (starting) attack and whom to contact, without making it too complex.

Checking inhalation technique repeatedly throughout the 1-year follow-up was associated with fewer hospitalization days. This repeated check is so often advocated, but difficult to implement. Actually, in the current literature there is not a large body of evidence really demonstrating that it works. ${ }^{20,24}$ Similarly, coaching patients on stopping smoking and providing them with pharmacological help repeatedly during the year was also associated with fewer hospitalization days. ${ }^{25}$ Another contribution we believe to be important was the so-called day 2 meeting in the hospital with caregivers, patient, and family. This meeting had three goals: to understand what contributed to hospitalization, exchange expectations regarding hospitalization, and anticipate on preparations needed for successful 


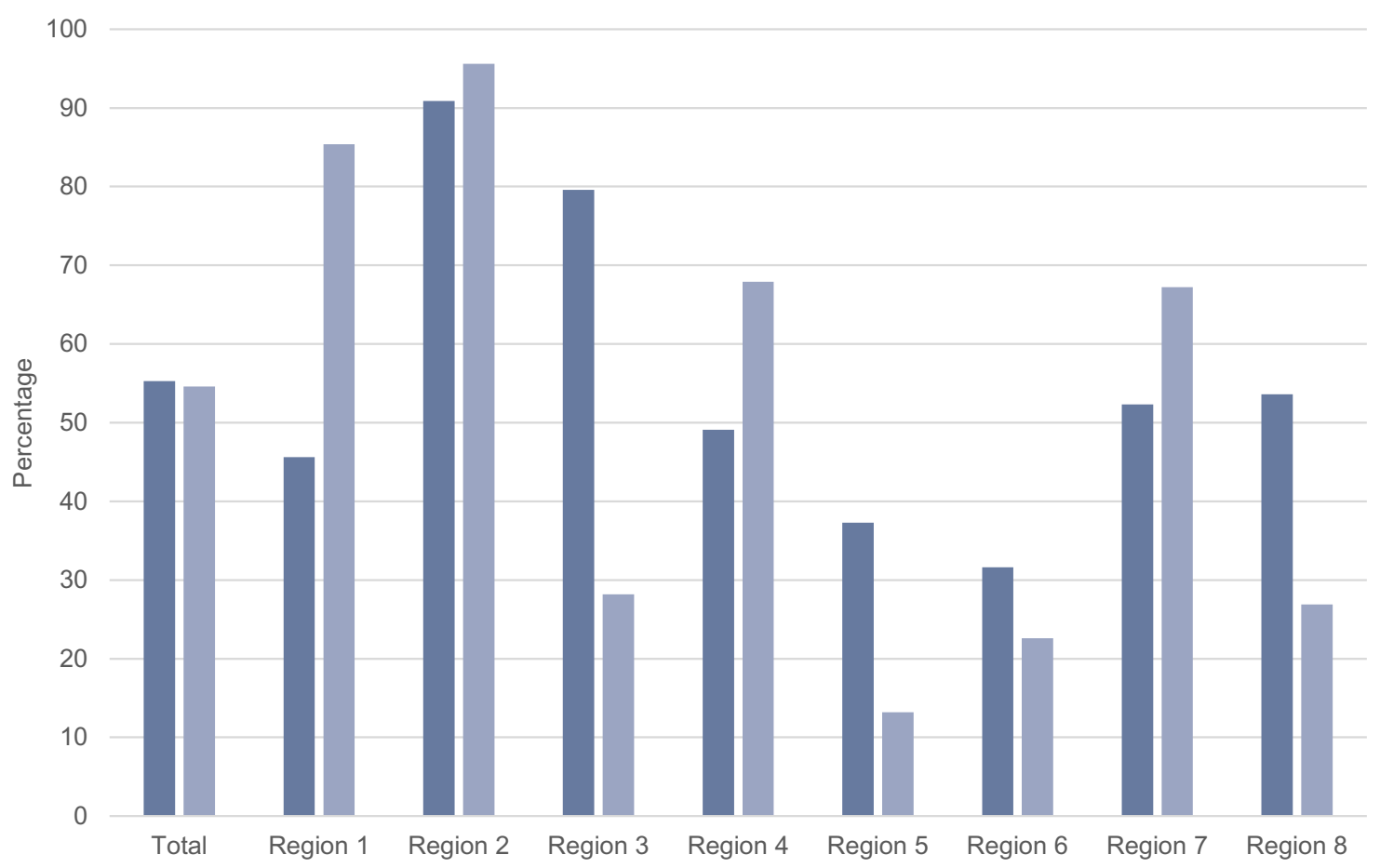

Figure 3 Variability in patient contact per region in the first week after discharge. Dark blue bars represent percentage of patients contacted in the first week after discharge, light blue percentage of patients for whom this contact was a home visit.

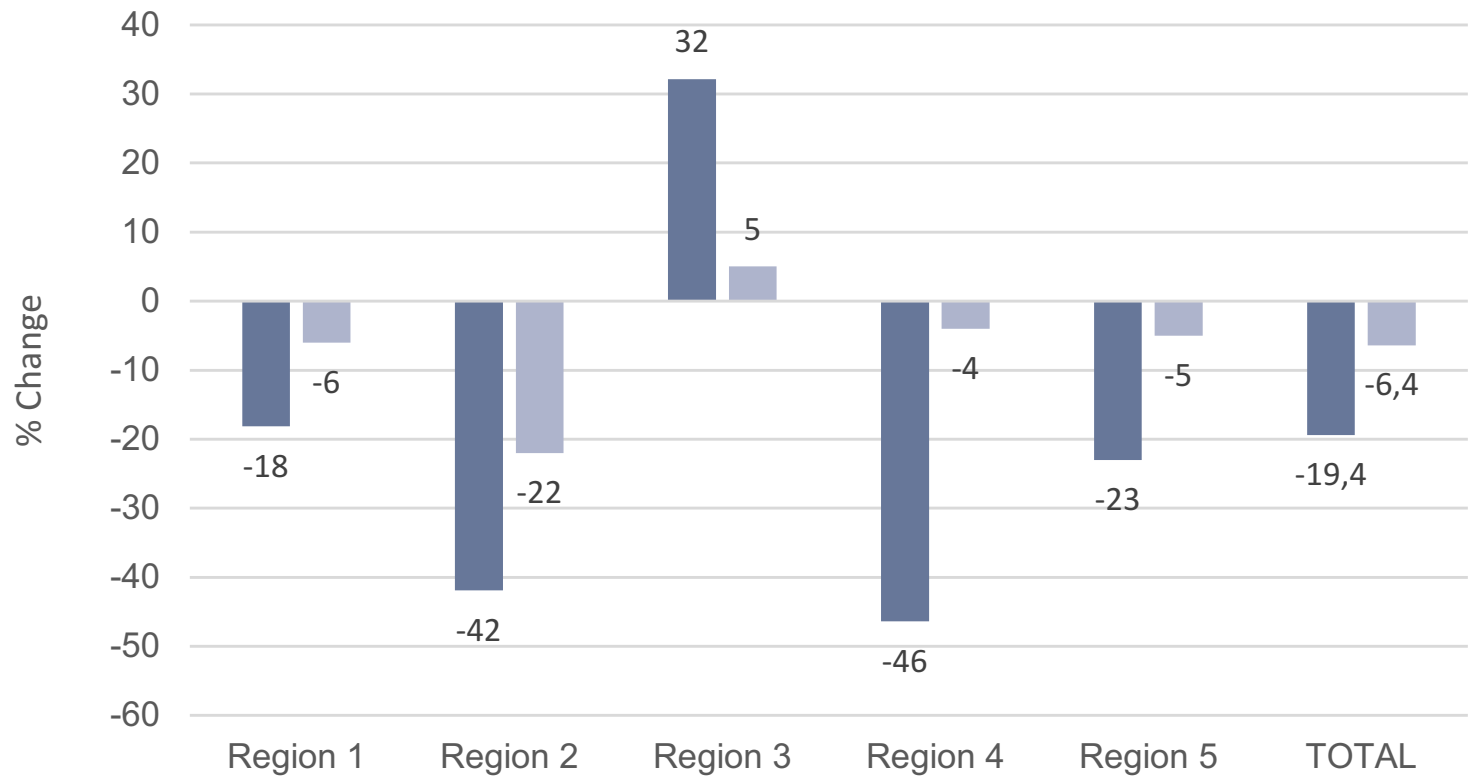

Figure 4 Overall change in COPD-admission days and COPD=readmission numbers between 2013 and 2018 per region and total. Dark blue bars represent percentage change in admission days; light blue percentage change in readmissions.

return home. We noticed that routine history-taking at the moment of hospitalization, frequently done by a junior doctor in the evening or at night, is focused on causal factors, such as infections, lack of medication compliance, and comorbidities. Asking patients on day 2 what contributed to the hospitalization, apart from the dyspnea they always have, led to the identification of quite different factors, such as reduced social support, anxiety, and depression. Making an early inventory of expectations of patients and their loved ones proved very useful. Conveying to patients on day 2 that the expected day of discharge is usually set at day 5 needs the explanation that 
it is not expected that all will be back to normal, but indeed that a patient will be better off at home than in the hospital. The third point on arrangements to be made for successful return home actually identifies factors that should not be postponed to the last day when checking the discharge bundle.

We were surprised to see that many interventions during hospitalization could not be positively associated with any reduction in hospitalization days (already starting in the hospital: smoking-cessation counseling, both nonpharmacological and pharmacological, discussing the lungattack action plan, and starting palliative-care discussions) or were even negatively associated (medication-inhalation check during hospitalization). A possible contribution to these unexpected outcomes is the fact that the program was quite loaded in the median 5 days of hospitalization. Consequently, more of the care and discussions should perhaps be inventoried only while the patient is still in hospital, but further discussed when more stable after discharge.

During the pilot study, we learned that we started off too ambitiously. The feedback from the participating health-care workers and from patients expressed that there were too many elements implemented in a short time in the hospital. In our new version of the care pathway, which is to be implemented nationwide, we have condensed the pathway to nine elements, and advocate starting with the three elements deemed most rewarding in the local context. ${ }^{26}$

Several other more general factors contributed to the overall favorable outcome. Above all, we believe the sense of urgency mattered: care just needs to improve, for many reasons.

Our setup was also important. This was a collaboration among hospital-based health workers, community health workers, and patients, united in the Lung Alliance Netherlands. The (limited) funding was in part from the Dutch Ministry of Health and the Innovation Fund of Dutch Insurers, but without any involvement with the content. While recruiting hospitals and associated primary-care groups, we were overwhelmed with a third of Dutch hospitals wanting to participate while being offered only start-up money. We could only accommodate eleven of the 33 hospital regions within our project. We believe that this signifies that there is a sense of urgency on the side of many caregivers inside and outside the hospital, as well as with patients who were actively involved.
The seven-phase method of the European Pathway Association described by Vanhaecht et al, a well-documented method, was utilized first at the national level for the general content, and thereafter within each participating hospital region. ${ }^{13}$ The latter allowed for a range of tailormade solutions with major local ownership when deciding how to implement key interventions and assess feasibility, and for exchange of these solutions among regions. As an example, the mentioned contact in the first week after discharge differed considerably between regions, anywhere from phoning the patient by a hospital-based nurse to home visits by a community home-care service.

The median number of hospitalization days we found compares favorably not only to control regions in the Netherlands but also to 2016 data from Belgium, Italy, and Portugal in a cluster-randomized trial. ${ }^{27}$ Actually, the median number of days per hospitalization was 12 in their study and five in ours. An important difference in design was the fact that the latter study was hospital-based only, as opposed to ours. Lively discussions and dedicated contact moments between caregivers inside and outside hospital were indeed fruitful, although it remains a challenge to involve GPs, given that an average GP has only a few patients with repeated hospitalizations under his or her care, accounting for sometimes greater involvement of pulmonologists in our endeavor than GPs. Importantly, our day 2 meeting and contact in the first week after discharge were different from their study.

Our study also has some important shortcomings. First of all, the process of reaching consensus on the ten key elements where biggest gains were expected was not formalized, eg, in a Delphi-type process, ${ }^{28}$ but the results of piloting these in practice are described in this manuscript. Second, this was a cohort study, instead of a randomized controlled trial, though we did have control regions for two major outcome variables. Also, no formal power calculation was made. Third, we had a considerable amount of missing data that we handled in a conservative way: when we were unsure whether a certain intervention was really provided to a patient, it was imputed as not given. Fourth, one region had a considerable relative increase in percentage of hospital days, from median 5 days to 6 . This region had implemented the home-care visits just before the start of our national pathway and had the lowest median number of hospitalization days in 2013. Additionally, they faced a merger of two hospitals during the study period. The increase they encountered underlines how difficult it is to maintain intensive dedicated care. 
Finally, it is prudent to consider a risk of bias while recruiting patients: we believe this to be limited, since we included the first 100 patients hospitalized for COPD per region with virtually no extra criteria, provided that they sufficiently mastered the Dutch language to be able to complete questionnaires.

In conclusion, with enthusiasm from within caregivers' groups and a sense of urgency, though even without large sums of money, we were able to reduce the number of hospitalization days considerably. Contact within 1 week of discharge proved important, and a dedicated meeting on day 2 was deemed very valuable as well. We also learned not to include too many elements at the same time when changing care during an increasingly short hospital stay. Some interventions are better pinpointed and prepared during hospitalization, but organized and implemented shortly after hospitalization. Finally, maintaining the enthusiasm and thus the effects found will be one of the next challenges. We are now spreading the pathway over more regions in the Netherlands, with pilot regions from this study in the role of ambassadors. Dedicated patient versions of the care pathway have been made, including video materials for explanations of exacerbations and of elements of high-quality care.

\section{The LAN COPD Care Pathway Study Group}

The LAN COPD Care Pathway Study Group consisted of: P Salomé (IJsselstein); L Sekhuis, E Rolink (Lung Alliance Netherlands, Amersfoort); L Westbroek, M Klijnsma, N de Voogd, J. Vonk, H Kerstjens (University Medical Center Groningen, Groningen); $\mathrm{H}$ in 't Veen, $\mathrm{N}$ Kuypers, A van Bruggen (Franciscus Gasthuis and Integrale Zorggroep Eerstelijn Rijnmond, Rotterdam); J van Campen, J van Exsel, T Nizet, $H$ de Jong, $M$ van Eggermont (Haaglanden Medical Center, Hagaziekenhuis and Hadoks, Arts en Zorg, The Hague), R Mies, M Bevers, E Beemsterboer (Slotervaart Hospital and Regionale Organisatie Huisartsen Amsterdam, Amsterdam); F van den Elshout, J van Dijke, E Fikkers (Rijnstate Hospital and Onze Huisartsen, Arnhem); G Wesseling, M Vaassen, J Hazelzet (Maastricht University Medical Center and Zorg in Ontwikkeling, Maastricht); R Meijer, R Riemersma, M Scholma, M de Vries (Ommelander Zorggroep Hospital and Stichting Eerstelijnszorg Appingedam and Groninger Huisartsen Coöperatie, Scheemda); H van Looij, W Oomen, E Korsmit, N Brouwers, R van Rijsewijk (Bravis Hospital and Zorggroep
West-Brabant, Roosendaal and Bergen op Zoom); B Alberts, $\mathrm{S}$ van Wolferen, D Martijnse, T Brouwer, $\mathrm{K}$ de Jong, J Brummelhuis, W Brinkman (Dijklander Hospital, location Purmerend, Zaans Medical Center, Stichting Eerstelijns Zorggroep and Evean); E Bergkamp (Spaarne Gasthuis, Haarlem); N Coenraad, B Holverda (Lung Foundation Netherlands, Amersfoort); J Muilwijk-Kroes (Cohaesie, Rotterdam); R van Snippenburg (Saltro, Utrecht); M Stegers (Canisius Wilhelmina Hospital, Nijmegen); A Stuurman-Bieze (Apotheek West, Emmeloord); D van Ranst (Revant, Breda); N Torrenga (Gezondheidscentrum Lombok, Utrecht); J Vercoulen (Radboud University Medical Center; Nijmegen); G van Vulpen-Handels (Stichting Eerstelijnsgezondheidszorg, Lelystad).

\section{Funding}

Partial funding for this study was received from the Dutch Innovation Funds (Innovatie Fonds), Dutch Ministry of Health, Welfare, and Sport, Lung Alliance Netherlands Support Fund, and Dutch Lung Fund. Additional funding in kind and/or cash was received from the participating hospitals and regional general practitioner organisations: Slotervaart Hospital and\& Regionale Organisatie Huisartsen Amsterdam, Amsterdam; Rijnstate Hospital and Onze Huisartsen, Arnhem; Haaglanden Medical Center, Hagaziekenhuis and Hadoks, Arts en Zorg, SHG, the Hague; Maastricht University Medical Center and Zorg in Ontwikkeling, Maastricht; Ommelanden Zorg Groep Hospital and Stichting Eerstelijnszorg Appingedam and Groninger Huisartsen Coöperatie, Scheemda, Groningen; Franciscus Gasthuis and Integrale Zorggroep Eerstelijn Rijnmond, Rotterdam; Bravis Hospital and Zorggroep West-Brabant, Roosendaal and Bergen op Zoom; and Dijklander Hospital, Purmerend, Zaans Medical Center, Zaandam, all located in the Netherlands.

\section{Disclosure}

Margot Klijnsma reports a grant from Lung Alliance Netherlands (LAN) during the conduct of the study. The authors report no other potential conflicts of interest for this work.

\section{References}

1. Global initiative for obstructive lung disease. Global strategy for the diagnosis, management, and prevention of chronic obstructive lung disease; 2019 report; 2019. Accessed 2019. Available from: https:// goldcopd.org/wp-content/uploads/2018/11/GOLD-2019-v1.7-FINAL14Nov2018-WMS.pdf. Accessed September 01, 2020. 
2. Seemungal TAHJ, Wedzicha JA. Exacerbation rate, health status and mortality in COPD-a review of potential interventions. Int J Chron Obstruct Pulmon Dis. 2009;203-223. doi:10.2147/COPD.S3385

3. Spencer SCP, Burge PS, Jones PW. Impact of preventing exacerbations on deterioration of health status in COPD. Eur Respir J. 2004;23(5):698-702. doi:10.1183/09031936.04.00121404

4. Donaldson GC, Seemungal TA, Bhowmik A, Wedzicha JA. Relationship between exacerbation frequency and lung function decline in chronic obstructive pulmonary disease. Thorax. 2002;57 (10):847-852. doi:10.1136/thorax.57.10.847

5. Wouters EF. Economic analysis of the confronting COPD survey: an overview of results. Respir Med. 2003;97(Suppl):C:S314. doi:10.10 16/S0954-6111(03)80020-3

6. Connors AF Jr, Dawson NV, Thomas C, et al. Outcomes following acute exacerbation of severe chronic obstructive lung disease. The support investigators (study to understand prognoses and preferences for outcomes and risks of treatments) [published erratum appears in am j respir crit care med 1997 Jan;155(1):386]. Am J Respir Crit Care Med. 1996;154(4 Pt 1):959-967. doi:10.1164/ajrccm.154.4. 8887592

7. Gunen H, Hacievliyagil SS, Kosar F, et al. Factors affecting survival of hospitalised patients with COPD. Eur Respir J. 2005;26(2):234 241. doi:10.1183/09031936.05.00024804

8. Groenewegen KH, Schols AM, Wouters EF. Mortality and mortalityrelated factors after hospitalization for acute exacerbation of COPD. Chest. 2003;124(2):459-467. doi:10.1378/chest.124.2.459

9. Foo J, Landis SH, Maskell J, et al. Continuing to confront COPD international patient survey: economic impact of COPD in 12 countries. PLoS One. 2016;11(4):e0152618. doi:10.1371/journal.pone.015 2618

10. Rutten-van Molken MP, Postma MJ, Joore MA, Genugten ML, Leidl $\mathrm{R}$, Jager JC. Current and future medical costs of asthma and chronic obstructive pulmonary disease in The Netherlands. Respir Med. 1999;93(11):779-787. doi:10.1016/S0954-6111(99)90262-7

11. Biewenga J, Kerstjens HAM, Rutgers MR, et al. Fighting chronic lung diseases on a national level: the Dutch national action programme. Int J Care Coord. 2016;19:65-72. doi:10.1177/205343451 6674659

12. Long Alliantie Nederland. Nationaal actieprogramma chronische longziekten. Available from: http:/www.longalliantie.nl/nationaalactieprogramma-chronische-longziekten/. Accessed June 11, 2019.

13. Vanhaecht K, Van-Gerven E, Deneckere S, et al. The 7-phase method to design, implement and evaluate care pathways. Int J Pers Cent Med. 2012;2:341-351.

14. van der Molen T, Willemse BW, Schokker S, Ten Hacken NH, Postma DS, Juniper EF. Development, validity and responsiveness of the clinical COPD questionnaire. Health Qual Life Outcomes. 2003;1:13. doi:10.1186/1477-7525-1-13

15. Centrum Klantervaring Zorg NIVEL. CQ-index Astma en COPD. 2013. Ervaringen met de zorg voor astma en/of COPD verkorte versie 2.o. Available from: https://www.zorginzicht.nl/ontwikkeltools/ontwikke len/overzicht-van-alle-cqi-vragenlijsten. Accessed October 08, 2019.
16. Centrum Klantervaring Zorg NIVEL. Vragenlijst CQI Ziekenhuisopname verkort; Published 2013. Available from: https:// www.zorginzicht.nl/ontwikkeltools/ontwikkelen/overzicht-van-allecqi-vragenlijsten. Accessed October 08, 2019.

17. Simmering JE, Polgreen LA, Comellas AP, Cavanaugh JE, Polgreen PM. Identifying patients with COPD at high risk of readmission. Chronic Obstr Pulm Dis. 2016;3(4):729-738. doi:10.15326/jcopdf.3. 4.2016.0136

18. Lawlor M, Kealy S, Agnew M, et al. Early discharge care with ongoing follow-up support may reduce hospital readmissions in COPD. Int J Chron Obstruct Pulmon Dis. 2009;4:55-60.

19. Budde J, Agarwal P, Mazumdar M, Braman SS. Follow-up soon after discharge may not reduce COPD readmissions. Chronic Obstr Pulm Dis. 2019;6(2):129-131. doi:10.15326/jcopdf.6.2.2018.0149

20. Lenferink A, Brusse-Keizer M, van der Valk PD, et al. Self-management interventions including action plans for exacerbations versus usual care in patients with chronic obstructive pulmonary disease. Cochrane Database Syst Rev. 2017;8:CD011682.

21. Jalota L, Jain VV. Action plans for COPD: strategies to manage exacerbations and improve outcomes. Int J Chron Obstruct Pulmon Dis. 2016;11:1179-1188. doi:10.2147/COPD.S76970

22. Lenferink A, van der Palen J, van der Valk P, et al. Exacerbation action plans for patients with COPD and comorbidities: a randomised controlled trial. Eur Respir J. 2019;54:5. doi:10.1183/13993003.02 134-2018

23. Holverda S, Rutgers MR, Kerstjens HAM. Time to rename COPD exacerbations: implementing the term lung attack. Lancet Respir Med. 2020;8(4):e25. doi:10.1016/S2213-2600(20)30123-5

24. Maricoto T, Monteiro L, Gama JMR, Correia-de-Sousa J, TabordaBarata L. Inhaler technique education and exacerbation risk in older adults with asthma or chronic obstructive pulmonary disease: a metaanalysis. J Am Geriatr Soc. 2019;67(1):57-66. doi:10.1111/jgs.15602

25. Josephs L, Culliford D, Johnson M, Thomas M. Improved outcomes in ex-smokers with COPD: a UK primary care observational cohort study. Eur Respir J. 2017;49:5. doi:10.1183/13993003.02114-2016

26. Long Alliantie Nederland. National care pathway for COPD lung attack with hospital admission. Available from: http://www.longallian tie.nl/files/8815/8833/4822/Dutch_National_care_pathway_COPD_ Lung_Attack.pdf. Accessed May 14, 2020.

27. Vanhaecht K, Lodewijckx C, Sermeus W, et al. Impact of a care pathway for COPD on adherence to guidelines and hospital readmission: a cluster randomized trial. Int J Chron Obstruct Pulmon Dis. 2016;11:2897-2908. doi:10.2147/COPD.S119849

28. Ospina MB, Michas M, Deuchar L, et al. Development of a patientcentred, evidence-based and consensus-based discharge care bundle for patients with acute exacerbation of chronic obstructive pulmonary disease. BMJ Open Respir Res. 2018;5(1):e000265. doi:10.1136/ bmjresp-2017-000265

\section{Publish your work in this journal}

The International Journal of COPD is an international, peer-reviewed journal of therapeutics and pharmacology focusing on concise rapid reporting of clinical studies and reviews in COPD. Special focus is given to the pathophysiological processes underlying the disease, intervention programs, patient focused education, and self management protocols. This journal is indexed on PubMed Central, MedLine and CAS. The manuscript management system is completely online and includes a very quick and fair peer-review system, which is all easy to use. Visit http://www.dovepress.com/testimonials.php to read real quotes from published authors. 